Cad.Est.Ling., Campinas, 47(1) e (2):61-67, 2005

\title{
QUESTÕES SOBRE O DESLOCAMENTO DO INVESTIGADOR EM AQUISIÇÃO DE LINGUAGEM ${ }^{1}$
}

\author{
GLÓRIACARVALHO \\ (Universidade Federal de Pernambuco)
}

\begin{abstract}
On the light of Cláudia Lemos's proposal, this article aims to focus on child's speech as the kernel of study in the field of language acquisition, evidencing the effect caused by such speech on the investigator. Consequently, it has led to the following deadlock: the recognition of an effect provoked on a subject constitutes that speech as the object of investigation, although such constitution suspends its objectivity status. In that sense, by means of the referring deadlock, the investigator would confront his/her study object question, which could lead him/her, in the case, to "resignify" investigation on language acquisition.
\end{abstract}

Gostaria de iniciar a minha participação, nesta mesa, através de Cláudia Lemos, quando, num dos seus mais recentes textos intitulado "Das vicissitudes da fala da criança e de sua investigação", refere-se "às mudanças de posição do investigador ao discernir as mudanças que a fala da criança pode mostrar" (De Lemos, 2002). Destaco, assim, a questão do efeito que a fala da criança (ou as suas mudanças) provocam sobre o investigador, isto é, de um modo bem geral, o efeito de tirá-lo de um certo lugar e lançá-lo em outros lugares, muitas vezes, incertos.

Considerando esse recorte, uma outra referência - que, de início, quero fazer ao trabalho de Cláudia Lemos - diz respeito à sua tomada de posição da qual têm sido tiradas conseqüências decisivas para o campo da aquisição de linguagem. Tal tomada de posição consiste na sua abordagem da mudança que ocorre, na criança, de uma condição de nãofalante, para uma condição de falante da língua, o que constitui a própria razão de ser desse campo de investigação.

Propõe essa autora que

"as mudanças que qualificam a trajetória da criança de infans a sujeito falante consistem em mudanças de posição, numa estrutura onde comparecem o outro (como instanciação da língua), a língua e a fala da criança” (De Lemos, 2000).

\footnotetext{
${ }^{1}$ Quero agradecer a Maria Fausta Pereira de Castro, por me ter dado a oportunidade de participar deste evento em comemoração dos "Vinte e Cinco anos do Projeto de Aquisição de Linguagem do IEL/UNICAMP: uma homenagem a Cláudia Lemos” e, através de Fausta, Ester Scarpa, Cecília Perroni e Rosa Figueira, agradeço e parabenizo a todos aqueles que constituem esse Projeto. Quero poder expressar o quanto me sinto privilegiada por ter tido Cláudia Lemos como orientadora de minha tese, por tê-la como amiga e ainda, posso dizer, como referência, no meu percurso, em Recife-PE, desde a realização do meu Doutorado, no IEL.
} 
Dessas colocações recortadas, pode-se inferir que qualquer coisa que se diga sobre a aquisição de linguagem deverá ser dita, a partir de relações (estruturais) que a criança mantém com o outro, com a língua e com a sua fala. Como consequiência, assume-se, então, que ninguém poderia escapar aos efeitos determinantes da relação com a língua, por mais singular que fosse essa relação, por mais singulares que fossem suas manifestações verbais, ou mesmo as ausências dessas manifestações.

Neste ponto, uma consequiência que se poderia tirar - no que concerne àquele que vê/ escuta a fala da criança - teria a seguinte forma: ao falar com (ou sobre) a criança, o sujeito que fala (mãe, pai, clínico, educador, investigador, etc.) somente poderia fazê-lo a partir de sua própria relação com a língua.

Desse modo, enquanto investigadores, no campo da aquisição de linguagem, falamos sobre a mudança, numa estrutura em que comparecem: a nossa fala, a fala da criança - em sua ligação com a fala do outro (mãe) e a língua - numa relação indissociável, singular e sujeita a deslocamentos.

Em outros termos, a trajetória de constituição da subjetividade da criança seria um efeito da referida estrutura, efeito esse que, simultaneamente, daria lugar à trajetória de constituição de qualquer sujeito que, de um modo ou de outro, estivesse implicado em tal estrutura.

O foco está sendo lançado, nestas reflexões, sobre o investigador como uma questão em aquisição de linguagem. Destaca-se, então, o peso que assume o problema do efeito. No que toca esse problema, vale apontar para o fato de que o peso do efeito está presente no conjunto de produções que se ligam ao Projeto de Aquisição de Linguagem do IEL/ UNICAMP. Cada um desses trabalhos, com suas peculiaridades, seguiram, de algum modo, a trilha aberta por Cláudia Lemos, na direção traçada pelo efeito, para tratar a sua questão específica.

Vale destacar que o termo efeito está sendo usado, aqui, tomando-se por base o sentido atribuído por Milner (1997), quando discute o efeito de prazer, no seu livro Le triple du plaisir. Para Milner, esse efeito se inscreve no alfabeto dos lugares do corpo, isto é, inscrevese na linguagem, a qual supõe o corpo e é por esse suposta. Por sua vez, um tal efeito, para ser provocado, requer uma física de qualidades materiais da coisa (na qual se inclui um outro corpo), qualidades essas que são também atravessadas pela linguagem.

Nesse sentido, de um modo geral, o efeito seria uma modificação provocada no corpo do sujeito por uma qualidade da coisa, supondo-se o corpo e a qualidade da coisa como sendo constituídos pela linguagem.

A esse respeito, quero, novamente, trazer Cláudia Lemos, através do seu texto "Sobre o paralelismo, sua extensão e a disparidade de seus efeitos", quando destaca a necessidade de se indagar sobre o que significa o fato de estruturas semelhantes produzirem efeitos tão díspares (De Lemos, a sair).

Essa autora formula tal indagação em relação ao paralelismo que se faz presente, na fala da criança, em determinado momento, assumindo que é a partir dessa indagação que se pode cernir o que é específico ao paralelismo da fala da criança.

Assim, repetindo, seria no caminho aberto pelo efeito que se poderiam diferenciar estruturas, aparentemente, semelhantes. E, por esse caminho, a referida autora nos faz ver 
Cadernos de Estudos Lingüísticos 47(1) e (2) - Jan./Dez. 2005

diferenças entre uma estrutura em que comparece o paralelismo da fala da criança e uma estrutura em que comparece o paralelismo poético.

Como marca de uma posição (a segunda) ocupada pelo infante, em sua trajetória de subjetivação, o paralelismo, juntamente com o erro previsível e a produção verbal insólita, indicam, mais visivelmente, um submetimento da criança ao funcionamento estrutural da língua - em seus dois pólos: metafórico e metonímico - funcionamento esse que foi ressignificado, por Cláudia Lemos, a partir de sua leitura de Saussure, de Jakobson e de Lacan.

Destaco essa segunda posição e assumo a abordagem de Maria Teresa Lemos que, ao conceber o erro do ponto de vista de um efeito que provoca no outro, recorta, especificamente, a questão do investigador em aquisição de linguagem. Essa autora analisa, então, o efeito de enigma ou efeito de estranhamento provocado pela fala da criança sobre o adulto (investigador), tomando como referência a experiência do estranho (segundo Freud), a qual é provocada pelo retorno de algo conhecido, mas que havia sido esquecido (Lemos, 2002). Nesse sentido, o enigma produzido pela fala da criança - com seu estatuto de inesperado - consiste numa possibilidade (ainda que esquecida) da língua. Consiste, pois, numa maneira singular de combinar significantes, a qual poderia ser apreendida pelo investigador, retroativamente, através de seus efeitos no corpo da teoria lingüística.

Seria, enfim, uma forma específica/singular de atuação dos processos metafóricos e metonímicos, forma essa que já havia sido esquecida pelo sujeito falante, mas que retorna na sua escuta da fala da criança, através de um efeito. Assim, uma qualidade da coisa (no caso, a fala da criança) estaria modificando o corpo (que vou chamar de corpo teórico) do investigador, fazendo retornar, nesse corpo, processos metafóricos e metonímicos esquecidos, ou melhor, uma combinatória de significantes esquecida.

Nessa perspectiva, a rigor, o investigador não apreenderia os processos metafóricos e metonímicos, na fala da criança. O que ele estaria, em última análise, apreendendo seriam os processos metafóricos e metonímicos que ocorreriam em si mesmo, na sua relação com a fala da criança. Ao que parece, somente reconhecendo, em si mesmo, os processos metafóricos e metonímicos que a sua escuta da fala da criança faz retornar, é que o investigador poderia reconhecer tais processos, na referida fala, ou melhor, somente se reconhecendo como uma instanciação da língua, é que ele poderia reconhecer a singularidade do infante, no seu instante de mudança. Em última instância, poder-se-ia propor que reconhecer aquele retorno dos processos metafóricos e metonímicos, pela via do efeito de estranhamento, estaria significando que, através do reconhecimento dessa mudança, em seu corpo, o investigador discerniria a mudança na fala da criança. Assim, pode-se dizer que o investigador se volta para si mesmo, a fim de encontrar a fala da criança.

Neste momento, gostaria de insistir sobre o que foi dito, no início destas reflexões, para destacar que o efeito, aqui discutido constitui, ao mesmo tempo, o investigador e a fala da criança, numa estrutura em que também comparecem a fala do outro e a língua.

Dizendo com outras palavras, nem o investigador, nem a fala da criança preexistiriam a tal estrutura. Não haveria possibilidade de se conceber nem o investigador nem a fala da criança fora dessa estrutura, ou seja, não haveria possibilidade de se conceber um lado de fora dessa estrutura, de onde o investigador olharia/escutaria a fala da criança (suposto objeto de seu estudo). 
Desse modo, coloca-se em questão a naturalidade do objeto de estudo, no campo da Aquisição de Linguagem, supondo-se que: o efeito provocado sobre o outro (no caso, o chamado investigador), pela fala da criança, constituiria tal fala, como objeto de investigação desse campo.

Relembrando o que já foi discutido, poder-se-ia dizer que seria no instante em que o investigador reconhecesse o mencionado efeito, que ele e o seu objeto de estudo estariam simultaneamente se constituindo.

Várias consequiências seriam tiradas dessa colocação; pretendo, no entanto, recortar apenas uma: do que foi posto até agora, poderíamos supor que, no campo de investigação da aquisição de linguagem, não existiria objeto de investigação; ou melhor, não existiria fala da criança como objeto de investigação, pois uma modificação, num sujeito, seria condição constitutiva dessa objetividade, no sentido de que seria condição para que esse sujeito viesse a cernir tal objeto.

Pergunta-se: não se estaria colocando aí uma impossibilidade? Isto é, se um campo de investigação se define em função de um objeto a ser investigado, segundo concepções epistemológicas, como poderia esse campo subsistir, na ausência de seu objeto?

Especificando um pouco mais o que foi colocado, diríamos que o efeito, enquanto constitutivo do objeto de estudo, o destituiria de sua substância e é nesse sentido que o destituiria de sua existência. Talvez se pudesse dizer que o efeito dessubstancializa o estatuto de objetividade e, portanto, coloca em questão esse estatuto.

Desde a Antigüidade grega, filósofos, como por exemplo, Aristóteles (apud Chaui, 1996) definiram a existência do objeto em função de algum tipo de relação entre a exterioridade de sua substância e a interioridade de sua representação.

Nesse sentido, Aristóteles fala em substância primeira para se referir aos seres individuais, realmente, existentes, com sua essência e seus acidentes. A substância segunda seriam os seres universais, isto é, os gêneros e espécies que não existem em si e por si mesmos, mas somente existem encarnados nos indivíduos, podendo, assim, ser conhecidos pelo pensamento. A metafísica aristotélica estaria, portanto, inaugurando o estudo da estrutura geral dos seres, ou as condições que fazem com que exista um "objeto" que possa ser conhecido pelo pensamento.

Nesse quadro, sem desconhecer as transformações que marcaram o conceito de objeto de estudo, pode-se propor que o estatuto de objetividade estaria vinculado a uma história cujo ponto nuclear seria o confronto entre exterioridade e interioridade, dando lugar a uma diversidade de direções.

Partindo, então, de Koyré (apud Julien, 1993), pode-se propor que, no tocante à concepção de objeto do saber científico, não teriam sido tiradas as consequiências da tentativa da física moderna de explicar o ser através do ser matemático. Em outras palavras, trata-se da tentativa de explicar os corpos que se movimentam, como sendo corpos matemáticos se deslocando num espaço matemático, o que, em última análise, significa uma submissão, à noção de letra, de noções como substância, existência, representação.

Neste momento, invoco, mais uma vez, Milner (1997), quando diz que a qualidade material e o efeito de prazer que ela provoca se colocam numa relação de impossibilidade. Em outras palavras, a ocasião do prazer, no universo moderno - que é um universo matematizado - consiste, estruturalmente, naquilo que faz desaparecer tal universo. 
Cadernos de Estudos Lingüísticos 47(1) e (2) - Jan./Dez. 2005

Transportando essas colocações para a singularidade do nosso campo, podemos supor que, se o efeito constitui a fala da criança como objeto de estudo, essa constituição não ocorre de modo simples nem pacífico, mas antes, ela tem lugar numa relação de impasse. Talvez se pudesse falar numa impossibilidade lógica da completude, já formulada por Gödel (apud Da Costa, 1980), na lógica clássica, através dos teoremas da incompletude.

Assim, numa época bastante inicial das investigações em lógica matemática, já se prenunciava um impasse que podemos chamar de impasse do todo, ou impasse da unidade: A (suposta) totalidade de um conjunto é gerada por proposições sobre essa totalidade; entretanto, tais proposições, ao mesmo tempo, negam a própria totalidade. Está incluída, nesse impasse, uma outra formulação: A totalidade é necessária para a apreensão do não todo e, ao mesmo tempo, é negada por este.

À luz do impasse da unidade, especificamente em aquisição de linguagem, podemos propor que o reconhecimento, por um sujeito, de um efeito provocado pela fala da criança - como vem sendo posto - é necessário para constituir essa fala como objeto de estudo, mas, ao constituí-la, a desfaz, isto é, a destitui de sua condição de objeto. Um tal impasse, que passamos a chamar de impasse do investigador ou impasse do objeto, já estava presente em minha Tese de Doutorado (Carvalho, 1995).

Nessa perspectiva, quando o investigador reconhece o efeito provocado sobre ele (pela fala da criança) ou mais ainda, quando ele reconhece que esse efeito é que constitui tal fala, não existe mais a fala da criança, em seu estatuto de objetividade. Dizendo de outro modo, um tal reconhecimento faria com que se desvanecesse a existência - concebida sob o ponto de vista da substância - e faria com que se desvanecesse também a oposição (ou mesmo a diferença) entre exterioridade e interioridade, na relação sujeito-objeto. Haveria o desvanecimento do objeto. Mas, seria somente nesses momentos de desvanecimento do seu objeto, isto é, nesses momentos de impasse, ou de reconhecimento do efeito, que apareceria o investigador e, com ele, se poderia pensar sobre um campo com um objeto a ser estudado, ou seja, com uma outra concepção de objeto. Entretanto, a investigação em aquisição de linguagem, ao aparecer nesses lugares de impasse, levaria o investigador a se confrontar, inevitavelmente, com singularidades, desafios, ameaças. Levaria, enfim, o investigador a se confrontar com o estatuto de objeto de estudo como uma questão colocada pela Instituição Científica.

Para cercar um pouco mais essa questão do impasse, gostaria, neste momento, de relembrar a colocação acima destacada: o investigador se voltaria para si mesmo, a fim de encontrar a fala da criança, ou melhor, ele se voltaria para uma mudança em si mesmo, para, nesse lugar, poder cernir uma mudança na fala da criança. E essa mudança, ao provocar estranhamento, ao surpreender pelo inesperado, estaria indicando uma quebra nas sínteses, na existência prévia, ou na suposta substância do seu objeto de estudo.

Assim, o próprio estranhamento apontaria para o impasse, na medida em que apontaria para uma quebra numa concepção prévia de fala da criança, ou seja, uma quebra numa substância ou numa consistência atribuídas, previamente, à fala da criança.

O referido impasse, por sua vez, parece apontar, também, para uma modificação no que havíamos colocado, anteriormente. Nesse sentido, ao invés de propormos que o investigador chegaria à fala da criança, através de si mesmo, talvez pudéssemos supor que o investigador 
chegaria a si mesmo através da fala da criança, ou melhor, ele iria à fala da criança e, ali, encontraria a si mesmo, como sendo um reflexo nesse espelho.

Vale destacar que, se de um lado essa modificação pode parecer uma proposta de recentramento do sujeito na figura do investigador, de outro lado, seria apenas um semblante de recentramento. Relembremos que tal modificação implica uma submissão de um sujeito a um efeito sobre o qual ele não pode exercer controle, através de seus conhecimentos ou de suas intenções. Isso implica, em última análise, um desafio, talvez o maior, em se tratando do investigador em aquisição de linguagem: o de se conceber como alguém que não possui controle sobre a língua, sobre a criança ou sobre o outro, ou melhor, como alguém que, assim como a criança e o outro, está assujeitado à língua, podendo assumir um compromisso com essa implicação e tentando tirar as consequiências desse compromisso, para o seu campo de estudo. Um tal compromisso consistiria, afinal, no compromisso ético de tentar não apagar, ou não esquecer, a sua condição de sujeito/submetido. Ou mais ainda, a sua condição de não ter o poder de transformar a criança em seu objeto de saber, ou de usar o consentimento dos pais ou responsáveis, como discute Leite (2002), à maneira de um escudo que o levaria a esquecer essa condição, ou seja, à maneira de uma legitimação que tornaria opaca a seguinte questão ética: esquecer a submissão a um efeito significaria afirmar - sem que se tenha conhecimento ou intenção - uma proposta de exercer domínio sobre o outro, qualquer que seja esse outro, isto é, significaria afirmar uma proposta de exercer domínio sobre um saber ou sobre um desejo do outro.

Colocando em outra direção: não faria sentido que o lugar a ser ocupado pelo investigador fosse um lugar onde um poder ou um domínio seria supostamente exercido, como talvez tenha sido tradicionalmente instituído ou ratificado pelo que se convencionou chamar de discurso científico.

Ao que tudo indica, trata-se de uma questão de natureza histórica, na medida em que parece extrapolar o campo específico da ciência e atingir o problema geral da dominação na sociedade humana.

Nesse sentido, parece que a tentativa de deslocamento ou de destituição do investigador desse lugar de domínio seria a condição constitutiva do campo da aquisição de linguagem.

Para finalizar, quero retomar mais uma colocação de Cláudia Lemos, do mesmo texto com que iniciei: "Das vicissitudes da fala da criança e de sua investigação". Diz essa autora:

Se com este trabalho, posso responder a esse convite é, porque, vindo de quem vem, ele me autoriza a colocar-me frente ao que me permite escrever "meu trabalho" ou "nosso trabalho", incluindo o trabalho daqueles que, movidos por suas próprias questões, reconheceram no "meu" um lugar onde alojá-las. (De Lemos, 2002, p. 41).

Quero dizer, Cláudia, que ao reconhecermos, no seu trabalho, um lugar onde alojarmos nossas questões, encontramos um lugar onde Ciência e Ética, ou melhor, Compromisso Científico e Compromisso Ético não podem se dissociar. Enfim, esse lugar, que você nos abriu, metaforiza o deslocamento do investigador em Aquisição de Linguagem. 


\section{REFERÊNCIAS BIBLIOGRÁFICAS}

CARVALHO, G.M.M. Erro de pessoa: levantamento de questões sobre o equívoco em aquisição da linguagem. 1995, Tese de Doutorado (inédita) DL/IEL,Unicamp, Campinas, SP.

CHAUI, M. (1996). Convite à filosofia. São Paulo: Ática.

DA COSTA, N. (1980). Ensaio sobre os fundamentos da lógica. São Paulo: Hucitec.

DE LEMOS, C. T. G. (2002). Das vicissitudes da fala da criança e de sua investigação. In: ORLANDI, E. (org.) Cadernos de Estudos Lingüísticos. História das idéias lingüísticas. Campinas, SP, n. 42, pp. 41-69, Jan./ Junho.

Sobre o paralelismo, sua extensão e a disparidade de seus efeitos. In M.F. Lier-de Vitto (org.) Sobre Aquisição, Patologias e Clínica de Linguagem, 2002 (no prelo).

. (2000). Questioning the notion of development: the case of language acquisition. Culture \& Psychology. SAGE Publications, New Delhi, v.6(2), pp. 169-182.

JULIEN, F. (1993). O retorno a Freud de Jacques Lacan: a aplicação ao espelho. Porto Alegre: Artes Médicas.

LEITE, N.V.A. Ética e Identidade. Trabalho apresentado na XIX Jornada de Estudos Lingüísticos do Nordeste - JELNE. Universidade Federal do Ceará. Fortaleza, Ceará, Setembro de 2002.

LEMOS, M.T. (2002). A Língua que me falta: uma análise dos estudos em Aquisição da Linguagem. Campinas: Mercado de Letras.

MILNER, J.C. (1997). Le triple du plaisir. Paris: Verdier. 